\title{
New Insights on Structures Forming the Lignin-Like Fractions of Ancestral Plants
}

\author{
Jorge Rencoret ${ }^{1 *}$, Ana Gutiérrez", Gisela Marques ${ }^{1}$, José C. del Río', Yuki Tobimatsu', \\ Pui Ying Lam², Marta Pérez-Boada ${ }^{3}$, Francisco Javier Ruiz-Dueñas ${ }^{3}$, José M. Barrasa ${ }^{4}$ \\ and Angel T. Martínez ${ }^{3 *}$
}

${ }^{1}$ Instituto de Recursos Naturales y Agrobiología de Sevilla (IRNAS), CSIC, Seville, Spain, ${ }^{2}$ Research Institute for Sustainable Humanosphere, Kyoto University, Kyoto, Japan, ${ }^{3}$ Centro de Investigaciones Biológicas "Margarita Salas" (CIB), CSIC,

Madrid, Spain, ${ }^{4}$ Departamento de Biología Vegetal, Universidad de Alcalá, Alcalá de Henares, Spain

In the present work, lignin-like fractions were isolated from several ancestral plants -including moss (Hypnum cupressiforme and Polytrichum commune), lycophyte (Selaginella kraussiana), horsetail (Equisetum palustre), fern (Nephrolepis cordifolia and Pteridium aquilinum), cycad (Cycas revoluta), and gnetophyte (Ephedra fragilis) speciesand structurally characterized by pyrolysis-gas chromatography-mass spectrometry (Py-GC/MS) and two-dimensional nuclear magnetic resonance (2D-NMR) spectroscopy. Py-GC/MS yielded marker compounds characteristic of lignin units, except in the H. cupressiforme, P. commune and E. palustre "lignins," where they were practically absent. Additional structural information on the other five samples was obtained from 2D-NMR experiments displaying intense correlations signals of guaiacyl $(G)$ units in the fern and cycad lignins, along with smaller amounts of $p$-hydroxyphenyl $(H)$ units. Interestingly, the lignins from the lycophyte $S$. kraussiana and the gnetophyte $E$. fragilis were not only composed of $\mathrm{G}$ - and $\mathrm{H}$-lignin units but they also incorporated significant amounts of the syringyl (S) units characteristic of angiosperms, which appeared much later in plant evolution, most probably due to convergent evolution. The latter finding is also supported by the abundance of syringol derivatives after the Py-GC/MS analyses of these two samples. Regarding lignin structure, $\beta-O-4^{\prime}$ alkyl-aryl ethers were the most abundant substructures, followed by condensed $\beta-5^{\prime}$ phenylcoumarans and $\beta-\beta^{\prime}$ resinols (and dibenzodioxocins in the fern and cycad lignins). The highest percentages of alkyl-aryl ether structures correlated with the higher S/G ratio in the S. Kraussiana and $E$. fragilis lignin-like fractions. More interestingly, apart from the typical monolignolderived lignin units $(H, G$ and $S)$, other structures, assigned to flavonoid compounds never reported before in natural lignins (such as amentoflavone, apigenin, hypnogenol B, kaempferol, and naringenin), could also be identified in the HSQC spectra of all the lignin-like fractions analyzed. With this purpose, in vitro synthesized coniferyl-naringenin and coniferyl-apigenin dehydrogenation polymers were used as standards. These flavonoids were abundant in $\mathrm{H}$. cupressiforme appearing as the only constituents of the moss lignin-like fraction (including 84\% of dimeric hypnogenol B) and their abundance decreased in those of $S$. Kraussiana (with amentoflavone and naringenin representing $14 \%$ of the total aromatic units), and the two ancient gymnosperms $(0.4-1.2 \%)$ and ferns $(0-0.7 \%)$. 


\section{INTRODUCTION}

The first land plants to colonize Earth, which evolved from freshwater green algae (Charophyceae), appeared around 450 Mya as confirmed by the fossil record (Kenrick and Crane, 1997). Because of the switch from an aqueous to a gaseous medium, early land plants faced key challenges related to increased environmental stresses (such as temperature fluctuations, desiccation, UV radiation, scarce nutrients, etc.). Therefore, land plants required significant metabolic adaptations to produce UV shields, antioxidants, and precursors for structural biopolymers to resist desiccation, improve light interception, and successfully adapt to terrestrial environments. In more advanced terrestrial plants, the aromatic lignin polymer (Weng and Chapple, 2010; Ralph et al., 2019) assumed some of the aforementioned functions (Raven, 1984; Qian et al., 2015; Xie et al., 2018). However, before land plants developed the ability to synthesize lignin, it is believed that flavonoid compounds were responsible for protecting them from UV radiation (Clayton et al., 2018; Davies et al., 2020).

Flavonoids are a large family of secondary metabolites ubiquitously found in land plants (Grotewold, 2006). These phenolic compounds, with a C6-C3-C6 carbon framework, are synthesized from phenylalanine and malonyl-CoA through the phenylpropanoid pathway. Flavonoids are usually found in either free and glycosylated forms. However, and especially thanks to the great advances in two-dimensional nuclear magnetic resonance (2D-NMR) spectroscopy during the last two decades, the presence of flavonoids incorporated into the lignin polymer has been discovered, acting as natural lignin monomers together with other phenolic precursors biosynthesized outside the monolignol pathway (del Río et al., 2020, 2021). In fact, all flavonoids with a free $4^{\prime}-\mathrm{OH}$ in the B-ring are potentially susceptible of being enzymatically oxidized, forming radicals compatible with lignification in cross-coupling reactions with monolignols.

The flavone tricin was the first discovered lignin-incorporated flavonoid, identified in wheat straw (del Río et al., 2012). Later, tricin was also found in many others monocots, especially from the Poaceae family (Rencoret et al., 2013, 2015; Lan et al., 2016b). The way tricin is incorporated into the lignin and its compatibility in cross-coupling reactions with monolignols have been studied extensively during the last years (Lan et al., 2015, 2016a). Furthermore, studies with genetically modified plants have demonstrated that some flavonoid intermediates in the tricin biosynthetic pathway, such as apigenin and naringenin, can also be incorporated into the lignin polymers of mutant plants (Lam et al., 2017, 2019), providing further evidence on the ability of flavonoids to act as true lignin monomers participating in cross-coupling reaction with traditional monolignols (del Río et al., 2020, 2021). Whereas in primitive plants, both free and lignin-incorporated flavonoids could contribute to plant protection against UV radiation, flavonoids in the lignin of more evolved angiosperms, such as grasses, would have a structural function as initiation points of the lignin chains, and their removal results in transgenic plants with lower lignin content as shown by blocking the biosynthesis of tricin (Lam et al., 2017).
The present work aims to study how lignin has evolved among different ancestral plants - from one of the most ancestral groups of terrestrial plants (mosses) to more evolved primitive gymnosperms - and to determine if flavonoids are present in their lignin-like fractions. For this purpose, lignin-like fractions were isolated by the dioxane method (Rencoret et al., 2015) from eight ancestral plants whose phylogenetic relationships are shown in Figure 1-including mosses Hypnum cupressiforme Hedw. and Polytrichum commune Hedw., lycophyte Selaginella kraussiana (Kunze) A. Braun, horsetail Equisetum palustre L., ferns Nephrolepis cordifolia (L.) C. Presl and Pteridium aquilinum (L.) Kuhn, cycad Cycas revoluta Thunb., and gnetophyte Ephedra fragilis Desf.- and their composition and structure were thoroughly characterized by a combination of analytical pyrolysis and 2D NMR.

\section{MATERIALS AND METHODS}

\section{Ancestral Plant Materials}

The plant material used in this study was collected from different locations: (i) P. commune and E. palustre from Rascafría (Madrid, Spain); (ii) H. cupressiforme and P. aquilinum from Burguete (Navarre, Spain); and (iii) C. revoluta, S. kraussiana, N. cordifolia and E. fragilis from the Juan Carlos I Royal Botanic Gardens (University of Alcalá, Madrid). The samples were air-dried and milled using a knife mill (Janke and Kunkel, Analysemühle). Non-structural lipophilic and hydrophilic compounds were removed by successive extractions with acetone, $80 \%$ ethanol, and water prior the isolation of lignin-like material. The extraction was carried out with acetone in a Soxhlet apparatus for $8 \mathrm{~h}$, and then with $80 \%$ ethanol $(3 \times 30 \mathrm{~min})$ and water $(3 \times 30 \mathrm{~min})$ in an ultrasonic bath.

\section{Isolation of Lignin-Like Fractions From Ancestral Plants}

Lignin-like fractions were isolated by the dioxane method with minor modifications (Evtuguin et al., 2001; Rencoret et al., 2015). Briefly, $8 \mathrm{~g}$ of the pre-extracted plant samples were refluxed under $\mathrm{N}_{2}(3 \times 40 \mathrm{~min}$, using fresh solution each time) with $80 \mathrm{~mL}$ of $0.2 \mathrm{M} \mathrm{HCl}$ in dioxane-water $(9: 1, \mathrm{v} / \mathrm{v})$. A final extraction was performed without addition of $\mathrm{HCl}$ in the dioxane-water mixture. The liquid phases were filtered and concentrated separately in a rotary evaporator at $40^{\circ} \mathrm{C}$ (up to approximately $20 \mathrm{~mL}$ ) to prevent lignin precipitation. Then, the concentrates were combined and precipitated in cold-water $(1,500 \mathrm{~mL})$ under stirring, centrifuged, and freeze dried. Finally, they were extracted with $200 \mathrm{~mL}$ of diethyl ether to remove low molecular weight contaminants. The dioxane lignin-like fractions yield represented 1-5\% of the plant material.

\section{Gel Permeation Chromatography}

Gel permeation chromatography (GPC) analysis of isolated lignin-like fractions was carried out on a Prominence-i LC2030 3D GPC system (Shimadzu, Kyoto, Japan) equipped with a photodiode array detector and a PLgel MIXED-D 


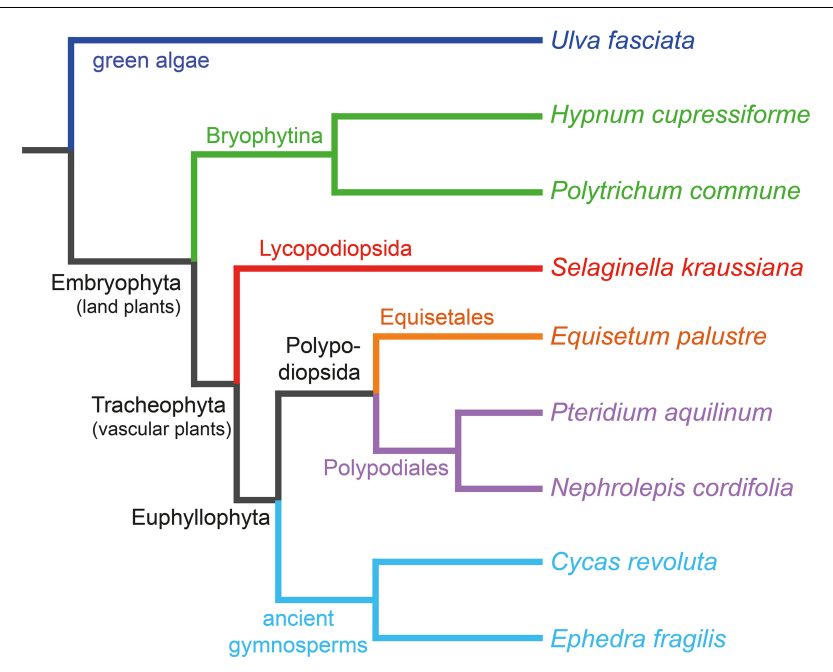

FIGURE 1 | Phylogenetic tree of the eight ancestral plants whose lignin-like fractions are analyzed, with the green alga Ulva fasciata Delile as an outsider to root the tree. Generated by phyloT v2 (https://phylot.biobyte.de/about.cgi).

column (Agilent Technologies, Stockport, United Kingdom), using the experimental conditions previously described (Rencoret et al., 2020).

\section{Pyrolysis Coupled to Gas Chromatography and Mass Spectrometry}

Analytical pyrolyses of the lignin preparations $(\sim 1 \mathrm{mg})$ were performed at $500^{\circ} \mathrm{C}(1 \mathrm{~min})$ in an EGA/PY-3030D microfurnance pyrolyzer (Frontier Laboratories Ltd., Fukushima, Japan) connected to a GC equipment 7820A (Agilent Technologies, Inc., Santa Clara, CA, United States) equipped with a DB-1701 fused-silica capillary column $(30 \mathrm{~m} \times 0.25 \mathrm{~mm}$ i.d., $0.25 \mu \mathrm{m}$ film thickness) and an Agilent 5975 MS selective detector (EI at $70 \mathrm{EV})$. The oven temperature was programmed from 50 to $100^{\circ} \mathrm{C}$ at $20^{\circ} \mathrm{C} \mathrm{min}^{-1}$ and then ramped to $280^{\circ} \mathrm{C}$ at a heating rate of $6^{\circ} \mathrm{C} \mathrm{min}-1$, and held for $5 \mathrm{~min}$. The released compounds were identified by comparison of their mass spectra with those in the literature (Ralph and Hatfield, 1991). Molar peak areas were calculated for the released lignin-derived products (specific markers) and the data for two replicates were averaged and expressed as percentages.

\section{D-NMR Spectroscopy}

For NMR analyses, $\sim 30 \mathrm{mg}$ of the lignin-like fractions were transferred into an NMR tube and dissolved in $0.6 \mathrm{~mL}$ of deuterated dimethylsulfoxide (DMSO- $d_{6}$ ). Heteronuclear single quantum coherence (HSQC) spectra were acquired at $300 \mathrm{~K}$ on a Bruker AVANCE III $500 \mathrm{MHz}$ spectrometer equipped with a $5 \mathrm{~mm}$ TCI cryogenic probe. The HSQC experiment was performed using a standard adiabatic pulse sequence (hsqcetgpsisp.2) and parameters already described (Rencoret et al., 2020). HSQC cross-peaks from flavonoid units were assigned by literature comparison (Lam et al., 2017, 2019), as well as by using flavonoid standards commercially available (for naringenin, kaempferol, apigenin and amentoflavone) and flavonoid-containing synthetic lignin (see below).

A semiquantitative analysis, based on HSQC signals integration, was performed using Bruker's TopSpin software. In the aromatic/unsaturated region, the $S_{2,6}, G_{2}, A p_{8}, K_{8}$ and $\mathrm{N}_{6,8}$ correlation signals were used to determine the relative abundances of the phenylpropane $S$ and $G$, and flavonoid apigenin (Ap), kaempferol (K) and naringenin (N) units, respectively. Since the $\mathrm{S}_{2,6}$ and $\mathrm{N}_{6,8}$ signals involve two protoncarbon pairs, their integration values were divided in half. In the case of the biflavonoid structures, their relative abundances were determined by integrating the $\mathrm{Am}_{6^{\prime \prime}}$ (amentoflavone) and $\mathrm{Hy}_{2}$ (hypnogenol B) signals. The $\mathrm{C}_{8} / \mathrm{H}_{8}$ and $\mathrm{C}_{2} / \mathrm{H}_{2}$ correlation signals of cinnamaldehyde end-units $(\mathrm{J})$ and ferulates (FA) were used to estimate their relative abundances. For quantification of inter-unit linkages resulting in different lignin substructures, the side-chain $\mathrm{C}_{\alpha} / \mathrm{H}_{\alpha}$ cross-signals of $\beta-O-4^{\prime}$ alkyl aryl ethers $\left(\mathrm{A}_{\alpha}\right), \beta-5^{\prime}$ phenylcoumarans $\left(\mathrm{B}_{\alpha}\right), \beta-\beta^{\prime}$ resinols $\left(\mathrm{C}_{\alpha}\right)$ and $5-5^{\prime}$ dibenzodioxocins $\left(\mathrm{D}_{\alpha}\right)$ were used.

\section{Standard Flavonoids and Synthetic Lignin Polymers}

Amentoflavone was purchased from Selleck (Houston, TX, United States), whereas naringenin [(2S)-4', 5,7-trihydroxyflavan4-one], kaempferol (3,4',5,7-tetrahydroxyflavone), and apigenin $\left(4^{\prime}, 5,7\right.$-trihydroxyflavone) were acquired from Sigma-Aldrich (Lyon, France). Synthetic lignins (dehydrogenation polymers, DHPs) from coniferyl alcohol/naringenin (GN-DHP) and coniferyl alcohol/apigenin (GA-DHP) were synthesized by the peroxidase-catalyzed dehydrogenative copolymerization of coniferyl alcohol $(0.425 \mathrm{mmol})$ with naringenin $(0.075 \mathrm{mmol})$ or apigenin $(0.075 \mathrm{mmol})$, respectively, using the so-called bulk

TABLE 1 | Weight-average $\left(M_{w}\right)$ and number-average $\left(M_{n}\right)$ molecular weights $\left(\mathrm{g} \mathrm{mol}^{-1}\right)$, and polydispersity $\left(M_{w} / M_{n}\right)$ of the lignin-like fractions isolated from ancestral plants.

Plant species ${ }^{a}$

\begin{tabular}{|c|c|c|c|c|c|c|c|c|}
\hline & $\mathrm{HC}$ & PC & SK & EP & NC & PA & CR & EF \\
\hline$M_{w}$ & 13,150 & 10,120 & 6,630 & 4,840 & 7,290 & 6,220 & 5,640 & 6,800 \\
\hline$M_{n}$ & 3,530 & 3,440 & 1,760 & 2,270 & 2,340 & 2,280 & 2,450 & 3,010 \\
\hline$M_{w} / M_{n}$ & 3.7 & 2.9 & 3.8 & 2.1 & 3.1 & 2.7 & 2.3 & 2.3 \\
\hline
\end{tabular}

${ }^{a} H C, H$. cupressiforme; PC, P. commune; SK, S. kraussiana; EP, E. palustre; NC, N. cordifolia; PA, P. aquilinum; CR, C. revoluta; EF, E. fragilis. 

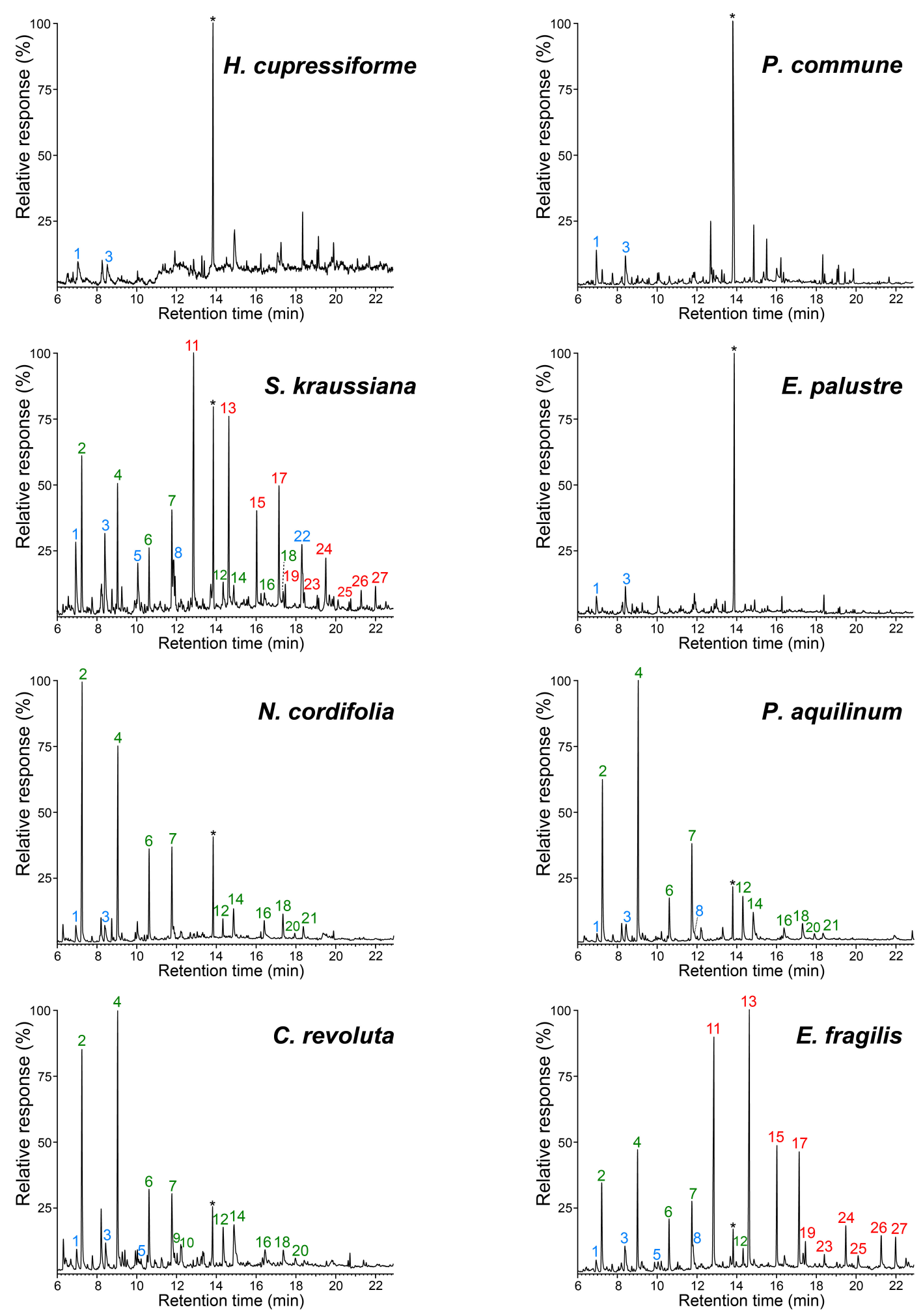

FIGURE 2 | Pyrograms of the lignin-like fractions isolated from the eight ancestral plants studied. Phenolic markers of $\mathrm{H}$, G, and S lignin units are labeled in blue, green and red, respectively. Peaks identities: phenol (1), guaiacol (2), 4-methylphenol (3), 4-methylguaiacol (4), 4-ethylphenol (5), 4-ethylguaicol (6), 4-vinylguaicol (7), 4-vinylphenol (8), eugenol (9), 4-propylguaiacol (10), syringol (11), trans-isoeugenol (12), 4-methylsyringol (13), vanillin (14), 4-ethylsyringol (15), acetovanillone (16), 4-vinylsyringol (17), guaiacylacetone (18), 4-allylsyringol (19), propiovanillone (20), guaiacyl vinyl ketone (21), 4-hydroxyacetophenone (22), cis-4-propenylsyringol (23), trans-4-propenylsyringol (24), syringaldehyde (25), acetosyringone (26), and syringylacetone (27). *Solvent stabilizer 4-methyl-2,6-ditertbutylphenol (rt $\sim 13.8$ min). 


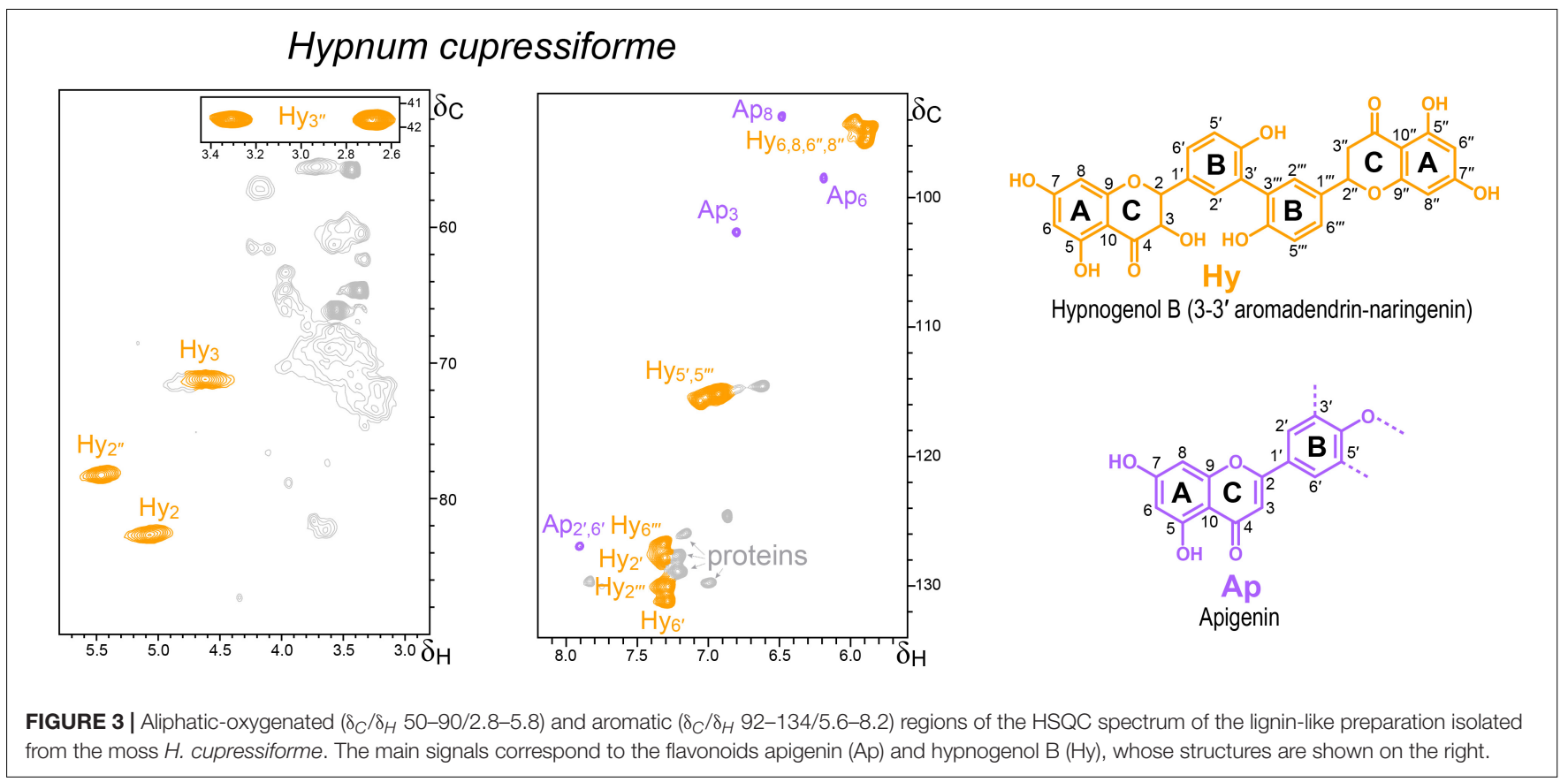

polymerization method (Tobimatsu et al., 2008) as previously described (Lam et al., 2017, 2019).

\section{RESULTS AND DISCUSSION}

\section{Molecular Weight Distributions of Lignin-Like Fractions From Ancestral Plants}

The weight-average $\left(\mathrm{M}_{w}\right)$ and number-average $\left(\mathrm{M}_{n}\right)$ molecular weights $\left(\mathrm{g} \mathrm{mol}^{-1}\right)$, and polydispersity index $\left(\mathrm{M}_{w} / \mathrm{M}_{n}\right)$ of the lignin-like fractions isolated from ancestral plants were determined by GPC analyses and are shown in Table 1. The data revealed that these fractions contain polymeric structures, as can be deduced from their $\mathrm{M}_{w}$ values that ranged from 4,840 to $13,150 \mathrm{~g} \mathrm{~mol}^{-1}$. Most of the lignin-like fractions analyzed presented a $\mathrm{M}_{w}$ comparable to other isolated lignins (Rencoret et al., 2020), with the exception of the ligninfractions from mosses, whose $\mathrm{M}_{w}$ were relatively higher $(13,150$ and $10,120 \mathrm{~g} \mathrm{~mol}^{-1}$ for $H$. cupressiforme and $P$. commune, respectively). Also, the polydispersity $\left(\mathrm{M}_{w} / \mathrm{M}_{n}\right)$ values of the lignin-like fractions were slightly higher in comparison to those observed for other isolated lignins (Rencoret et al., 2020).

\section{Lignin Composition of Ancestral Plants as Shown by Analytical Pyrolysis}

The ancestral lignin-like fractions of the plants studied were firstly analyzed by pyrolysis coupled to gas chromatography and mass spectrometry (Py-GC/MS), a highly sensitive method that can provide information on their relative composition in terms of syringyl (S), guaiacyl $(\mathrm{G})$ and $p$-hydroxyphenyl $(\mathrm{H})$ units (as H:G:S ratio). By Py-GC/MS (Figure 2) all the ligninlike fractions, with the exception of those from the mosses
(H. cupressiforme, P. commune) and the horsetail (E. palustre), released characteristic lignin markers. Despite small amounts of phenol and 4-methylphenol were found among the pyrolysis products of these three lignins, the absence of H-type markers with longer side-chains (such as 4-ethylphenol, eugenol or 4-propenylphenol) indicates that they do not actually come from lignin but more likely from other compounds, such as proteins or flavonoids that also yield these $\mathrm{H}$-type compounds upon pyrolysis. It is therefore possible to conclude the absence of recognizable lignin building blocks in the mosses and horsetail studied here.

$S$-lignin markers were the most abundant in the pyrograms of the gnetophyte (E. fragilis) and the lycophyte (S. kraussiana) lignin-like fractions, while G-lignin markers predominated in the rest of samples, as in the cycad (C. revoluta), and the ferns ( $P$. aquilinum and $N$. cordifolia) lignins. The pyrogram of the $S$. kraussiana fraction showed an unusually high peak of 4-hydroxyacetophenone (peak 22), which was absent in other H-rich lignins (Rencoret et al., 2016). Therefore, it would be logical to think that it is not derived from $\mathrm{H}$-lignin but comes from other lignin-related compounds containing $p$-hydroxyphenyl moieties in their structures, as will be shown below.

\section{In-Depth Structural Analysis of Ancestral Lignins by 2D-NMR}

After the initial Py-GC/MS study of lignin composition, 2DNMR analyses of the isolated lignin-like fractions provided additional valuable information about their composition in flavonoid and conventional lignin ( $\mathrm{H}, \mathrm{G}$, and $\mathrm{S})$ units, as well as on their inter-unit linkages resulting in different substructures. The main correlation signals identified in the HSQC spectra discussed in the following subsections (Figures 3-6) are listed in 
TABLE 2 | Assignments of the ${ }^{1} \mathrm{H} /{ }^{13} \mathrm{C}$ signals identified in the HSQC spectra (Figures 3-6) of the lignin-like fractions isolated from the ancestral plants studied.

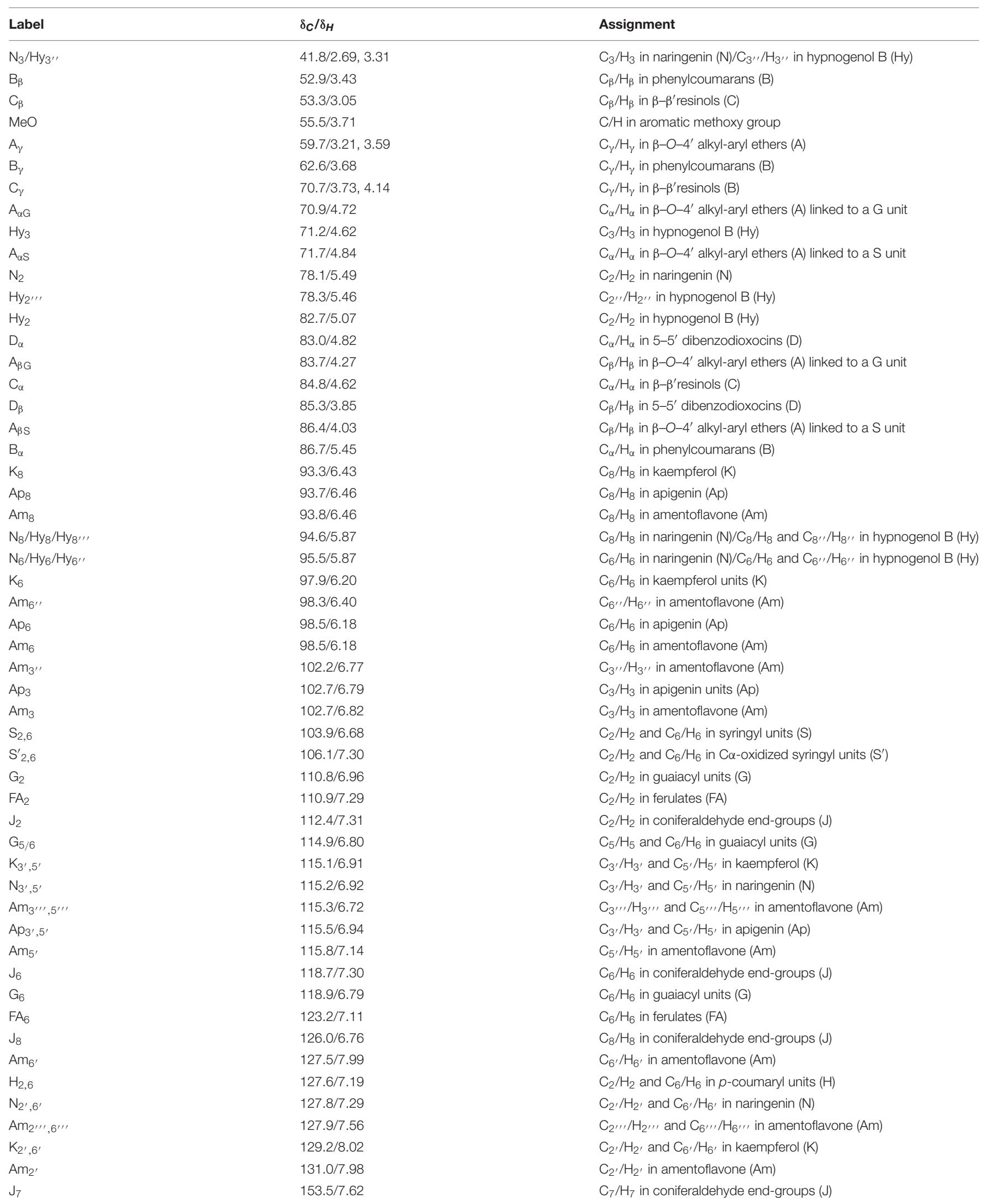


TABLE 3 | Semiquantitative analysis of lignin aromatic units (flavonoid units included) and different substructures, from integration of HSQC spectra (see Figures 3-6 also showing structural formulae) of the lignin-like fractions from ancestral plants.

\begin{tabular}{|c|c|c|c|c|c|c|}
\hline & \multicolumn{6}{|c|}{ Plant species ${ }^{a}$} \\
\hline & $\mathrm{HC}$ & SK & NC & PA & CR & EF \\
\hline \multicolumn{7}{|l|}{ Aromatic units $(\%)^{b}$ : } \\
\hline p-Hydroxyphenyl $(\mathrm{H})$ & - & 5.8 & - & 0.5 & 0.7 & 0.5 \\
\hline Guaiacyl (G) & - & 25.9 & 100 & 98.8 & 98.7 & 27.0 \\
\hline Syringyl (S) & - & 54.2 & - & - & - & 71.3 \\
\hline Naringenin $(\mathrm{N})$ & - & 2.5 & - & - & 0.2 & - \\
\hline Apigenin (Ap) & 16.0 & - & - & & - & - \\
\hline Kaempferol (K) & - & - & - & 0.7 & - & 1.2 \\
\hline Amentoflavone (Am) & - & 11.6 & - & - & 0.4 & \\
\hline Hypnogenol B (Hy) & 84.0 & - & - & - & - & - \\
\hline \multicolumn{7}{|l|}{ Lignin substructures $(\%)^{c}$ : } \\
\hline$\beta-O-4^{\prime}$ Alkyl-aryl ethers (A) & - & $88.9(57.5)$ & $66.2(19.6)$ & $58.3(28.6)$ & $59.5(32.6)$ & $81.2(54.6)$ \\
\hline$\beta-5^{\prime}$ Phenylcoumarans (B) & - & $6.4(4.2)$ & $25.3(7.5)$ & $26.8(13.1)$ & $24.9(13.6)$ & $7.0(4.7)$ \\
\hline$\beta-\beta^{\prime}$ Resinols $(C)$ & - & $4.7(3.0)$ & $5.5(1.6)$ & $5.5(2.7)$ & $5.4(3.0)$ & $10.6(7.1)$ \\
\hline 5-5' Dibenzodioxocins (D) & - & - & $3.0(0.9)$ & $3.9(1.9)$ & $5.9(3.2)$ & - \\
\hline Coniferaldehyde end-groups $(\mathrm{J})$ & - & - & - & $5.5(2.7)$ & $4.3(2.3)$ & $1.2(0.8)$ \\
\hline
\end{tabular}

${ }^{a} H C, H$. cupressiforme; SK, S. kraussiana; NC, N. cordifolia; PA, P. aquilinum; CR, C. revoluta; EF, E. fragilis.

${ }^{b}$ As percentage of total aromatic units $(H+G+S+N+A p+K+A m+H y=100)$.

${ }^{c}$ As percentage of total substructures $(A+B+C+D+J=100)$, with values in parentheses referred to classical lignin units $(H+G+S=100)$.

- , not detected.

Table 2, and a semiquantitative summary of the different spectra is provided in Table 3. Significant differences were found in the composition and structure of the lignin-like preparations from the different ancestral plants, as detailed below.

\section{Mosses}

Several studies indicate that liverworts and mosses were the earliest colonizers of the land (Kenrick and Crane, 1997). The presence of significant amounts of the classical lignin structures (typically formed by $\mathrm{H}, \mathrm{G}$ and/or $\mathrm{S}$ units) in the mosses $H$. cupressiforme (class Bryopsida) and $P$. commune (class Polytrichopsida) could be discarded by the Py-GC/MS analyses as discussed above. However, the presence of flavonoidtype polyphenols was suggested by the HSQC analyses, as discussed below.

The HSQC spectrum of the lignin-like fraction from H. cupressiforme (Figure 3) displayed correlation signals of flavonoids and proteins. The chemical shifts of the strongest flavonoid signals were consistent with hypnogenol $\mathrm{B}$, a biflavonoid composed of aromadendrin [(2R,3R)-3, $4^{\prime}, 5,7$ tetrahydroxyflavan-4-one] and naringenin linked by a 3-3' bond, which has been found in the extracts of $H$. cupressiforme (Sievers et al., 1992). The characteristic signals of the naringenin C-ring were clearly observed at 78.3/5.46 ( $\left.\mathrm{Hy}_{2}{ }^{\prime \prime}\right)$ and 41.8/2.69 and $41.8 / 3.3\left(\mathrm{Hy}_{3}{ }^{\prime \prime}\right)$ ppm, whereas the equivalent signals of the aromadendrin C-ring seem to be those detected at 82.7/5.07 $\left(\mathrm{Hy}_{2}\right)$ and $71.2 / 4.62 \mathrm{ppm}\left(\mathrm{Hy}_{3}\right)$ (these assignments could not be fully confirmed since hypnogenol $\mathrm{B}$ is not commercially available). In addition to hypnogenol B, distinctive HSQC signals of the A- and C-rings of the flavone apigenin were also detected. These and other signals were assigned using as reference the
HSQC spectra of authentic flavonoid standards as well as DHPs prepared by copolymerization of apigenin or naringenin with coniferyl alcohol (Supplementary Figure 1). $\mathrm{Ap}_{8}, \mathrm{Ap}_{6}$, and $\mathrm{Ap}_{3}$ signals matched well with those of the apigenin authentic standard. In contrast, the signals of apigenin B-ring did not exactly match those of free apigenin (this is only appreciable for the $\mathrm{Ap}_{2^{\prime}, 6^{\prime}}$ since $\mathrm{Ap}_{3^{\prime}, 5^{\prime}}$ would overlap with the hypnogenol $\mathrm{B}$ $\mathrm{Hy}_{5^{\prime}, 5^{\prime \prime}}$ signal), indicating that apigenin in the H. cupressiforme sample could be linked through its B-ring.

On the contrary, the HSQC spectrum of the $P$. commune lignin-like fraction preparation was saturated by protein signals (Supplementary Figure 2). Although trace amounts of G- and H-lignin units had been reported in P. commune after cupric oxide alkaline degradation of whole material (Logan and Thomas, 1985), we could only detect H-type signals upon pyrolysis, which could arise from protein moieties. The HSQC spectrum of $P$. commune confirmed the occurrence of proteins (Kim et al., 2017) and the absence of H-lignin units in the lignin-like preparation isolated from this moss. The presence of lignin in mosses is controversial since lignin was always thought to be a unique component of vascular plants (Erickson and Miksche, 1974). Moreover, as in the case of the $H$. cupressiforme lignin-like preparation, some flavonoid signals (tentatively assigned to naringenin and kaempferol) could be also present in the P. commune "lignin," albeit with low intensities and overlapped with the protein signals.

Interestingly, the flavonoids tentatively identified in the moss "lignin-like" preparation (as well as in all the other lignin-like fractions) present a B-ring structurally similar to the H-lignin units. Perhaps, this is the reason why a previous study that intended to clarify the presence/absence of lignin in Sphagnum 
magellanicum Brid. by ${ }^{13} \mathrm{C}$ NMR reported the presence of H-lignin in this moss (Nimz and Tutschek, 1977). However, the characteristic signals of lignin linkages were lacking and the most probable conclusion is that the signals detected by the authors corresponded to flavonoids with an H-type B-ring and not to real H-lignin units.

\section{Lycophytes}

Lycophytes (class Lycopodiopsida) appeared about 400 Mya and are among the earliest terrestrial vascular plants, with the Selaginellaceae family including more than 700 species (Jermy, 1990). Their characteristic giant species, represented by extinct arborescent plants with secondary thickening in their trunks and rhizomorphs (such as Lepidodendron and Sigillaria in the order Lepidodendrales, and Pleuromeia in the order Isoetales), dominated the Earth flora during the Carboniferous period. Selaginellaceae together with two other lycophyte families (Lycopodiaceae and Isoetaceae) constitute the oldest lineage of vascular plants surviving on Earth (Banks, 2009). Interestingly, reduction of vegetative structures was a recurrent phenomenon along lycophyte evolution (Bateman, 1996). Thus, extant Selaginella and Isoetes are herbaceous and rhizomatous species maintaining reminiscences of giant arborescent lineages with secondary thickening. Among the Selaginella species, S. kraussiana was selected for this study since its lignin has not been studied before.

The HSQC analysis of the lignin-like preparation obtained from S. kraussiana (Figure 4) reveals that this primitive vascular plant has a lignin composed of not only G- and H-units, but also of significant amounts of S-units. The latter are characteristic of angiosperms that appeared much later in time, which indicates convergent evolution of S-lignin in lycophytes and angiosperms. The presence of $S$ units in the lignin of other Selaginella species has been previously shown by different techniques, including $\mathrm{CuO}$ alkaline degradation (Logan and Thomas, 1985), acidolysis, nitrobenzene oxidation, FTIR, ozonation, ${ }^{1} \mathrm{H}-\mathrm{NMR}$ (Jin et al., 2005, 2007a), derivatization followed by reductive cleavage (Weng et al., 2008), and 2D-NMR (Weng et al., 2011). The aliphatic oxygenated region of the HSQC spectrum shows the methoxyl signal together with those of typical lignin substructures (Figure 4). $\beta-O-4^{\prime}$ alkyl-aryl ethers (A) are the most abundant linkages ( $89 \%$ of the total) observed in the HSQC spectrum of the $S$. kraussiana lignin-like fraction, followed by lower amounts (around 5\%) of $\beta-5^{\prime}$ phenylcoumarans (B) and $\beta-\beta^{\prime}$ resinols $(\mathrm{C})$ (Table 3 ).

Together with the aforementioned lignin signals, the aromatic region of the HSQC spectrum of the S. kraussiana lignin-like fraction also showed signals of flavonoids (Figure 4). At a first glance, several of them seemed to match well with those of the flavone apigenin (Supplementary Figure 1) but a more extensive analysis revealed that they actually corresponded to the biflavonoid amentoflavone (bis-apigenin coupled at 8 and $3^{\prime}$ positions) and the flavanone naringenin, the latter being less abundant. The identities of these signals were confirmed by spectral comparison with authentic flavonoid standards and synthetic DHPs (Supplementary Figure 1).
Among over 130 natural products reported from Selaginella species (Weng and Noel, 2013), amentoflavone is the most common (bi)flavonoid (Setyawan, 2019), being also present in Euphorbiaceae, Calophyllaceae and other plants, and exhibiting a variety of pharmacological properties (Yu et al., 2017). Free amentoflavone can be easily isolated from Selaginella plants by ethanol extraction (Swamy et al., 2006). So, considering that the S. kraussiana material analyzed was successively and exhaustively extracted with several solvents (acetone, ethanol, and water), and the dioxane-lignin preparation was purified as well (with diethyl ether), it is logical to think that the amentoflavone present in this fraction is somehow bound to the lignin polymer. Another fact supporting this hypothesis is the relatively lower intensities of the $\mathrm{Am}_{5^{\prime}}$ and $\mathrm{Am}_{2}$ ' signals (compared to $\mathrm{Am}_{6}$, $\mathrm{Am}_{8}, \mathrm{Am}_{6^{\prime \prime}}$ and $\left.\mathrm{Am}_{2^{\prime \prime \prime}}, 6^{\prime \prime \prime}\right)$, which suggests that amentoflavone would be connected to the lignin through its B-ring. It is believed that biflavonoids are biosynthesized through dimerization of monomeric flavonoids via radical coupling reactions catalyzed by peroxidases (and/or laccases) (Yamaguchi and Kato, 2012) in the same way in which lignin polymerizes from monolignols (Ralph et al., 2004).

A "milled-wood lignin" (MWL) preparation was also isolated from S. kraussiana by the classical procedure (Björkman, 1956), which is expected to be representative of the native lignin (Fujimoto et al., 2005). The HSQC spectrum of the S. kraussiana MWL was very similar to that of the dioxane-lignin (Supplementary Figure 3) and also displayed amentoflavone signals with almost identical relative abundances, reinforcing the idea that this biflavonoid might be incorporated into the lignin structure. More research is currently in progress to confirm whether the amentoflavone is covalently linked to the lignin in this Selaginella species.

Interestingly, in a previous work, signals for amentoflavone can also be clearly observed in the HSQC spectrum of the lignin isolated from Selaginella moellendorffi Hieron., although they were not assigned there (Weng et al., 2011). It is important to note that in that work the lignin was acetylated and, therefore, the chemical shifts of the amentoflavone signals were slightly different (this point was confirmed by acetylating S. kraussiana and recording HSQC under the same experimental conditions). Therefore, the present work reports for the first time the presence of amentoflavone in the lignin fraction of a Selaginella species. The occurrence of amentoflavone explains the appearance of 4-hydroxyacetophenone (peak 22) in the pyrograms of the S. kraussiana lignin (Figure 2) since 4-hydroxyacetophenone was the main compound released by pyrolysis of an amentoflavone standard (data not shown).

\section{Horsetails}

Despite being a vascular plant, the lignin-like preparation from the horsetail E. palustre (class Polypodiopsida, order Equiseales) did not yield significant amounts of pyrolysis lignin markers and only traces of phenol and 4-methylphenol, which could arise from proteins and not from real H-lignin units, could be detected (Figure 2 peaks 1 and 4, respectively). This could be related to the limited development of its vascular system with no secondary thickening (Logan and Thomas, 1985) and 


\section{Selaginella kraussiana}

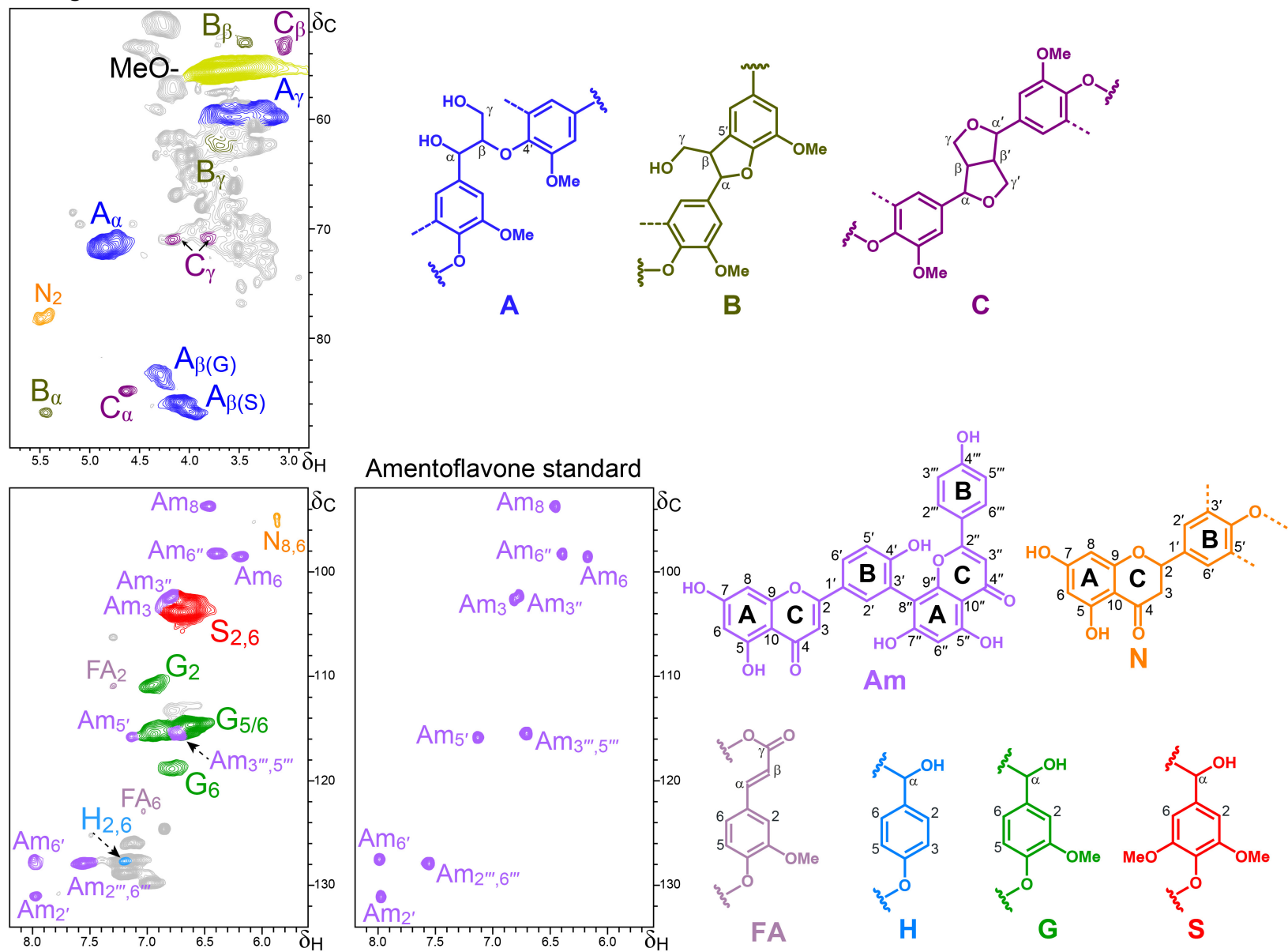

FIGURE 4 | Aliphatic-oxygenated $\left(\delta_{C} / \delta_{H} 50-90 / 2.8-5.8\right)$ and aromatic $\left(\delta_{C} / \delta_{H}\right.$ 92-134/5.5-8.2) regions of the HSQC spectrum of the $S$. kraussiana lignin-like preparation. The HSQC spectrum of authentic amentoflavone is also shown for comparison. The main structures identified $-\mathrm{corresponding}$ to $\beta-\mathrm{O}-4^{\prime}$ ether $(\mathrm{A})$, $\beta-5^{\prime}$ phenylcoumaran $(B)$ and $\beta-\beta^{\prime}$ resinols $(C)$ side chains, $p$-hydroxyphenyl $(H)$, guaiacyl $(G)$ and syringyl $(S)$ units, and ferulic acid $(F A)$, amentoflavone (Am) and naringenin $(\mathrm{N})$ moieties - are depicted.

its wetland-adapted lifestyle. The HSQC spectrum showed significant amounts of proteins, which would explain the release of phenol and 4-methylphenol upon Py-GC/MS and confirm the absence of $\mathrm{H}$-lignin units (Supplementary Figure 2). Lignin-derived compounds have been previously reported, although in very low amounts, in other horsetails by chemical degradation of whole cell-wall material (Logan and Thomas, 1985; Espiñeira et al., 2011).

\section{Ferns}

The aromatic regions of the HSQC spectra (Figure 5) of the lignin-like preparations isolated from the ferns $P$. aquilinum and N. cordifolia (class Polypodiopsida, order Polypodiales) showed almost exclusively signals for G-lignin $\left(G_{2}, G_{5}\right.$, and $\left.G_{6}\right)$, together with small signals for H-lignin units in the spectrum of $P$. aquilinum. Correlation signals of coniferaldehyde end-groups $\left(\mathrm{J}_{2}, \mathrm{~J}_{6}\right.$, and $\left.\mathrm{J}_{8}\right)$ and flavonoids were also detected.

In the case of $P$. aquilinum, the flavonoid signals were unambiguously assigned to kaempferol (by comparison with an authentic standard, Supplementary Figure 1), whereas in the case of $N$. cordifolia, it was not possible to conclusively assign them (unknown signals labeled with question marks) (Figure 5). The occurrence of kaempferol in $P$. aquilinum is not limited to the lignin fraction but its presence, mainly as kaempferol glycosides, has also been reported in the ethanol extracts (Nakabayashi, 1955; Imperato, 1996).

Analysis of signals in the aliphatic-oxygenated region of the spectra showed that $P$. aquilinum and $N$. cordifolia present a rather similar linkages distribution (Table 3). Apart from the signal of methoxyl groups (in G-units), typical signals of different inter-unit linkages were clearly detected, including $\beta-O-4^{\prime}$ alkyl-aryl ethers (A), $\beta-5^{\prime}$ phenylcoumarans (B), $\beta-\beta^{\prime}$ resinols (C) and 5-5' dibenzodioxocins (D).

\section{Ancient Gymnosperms (Cycads and Gnetophytes)}

To have a broader view on lignin in early plants, the lignin-like fractions of two ancestral gymnosperms (division Spermatophyta) with secondary thickening, C. revoluta (class 


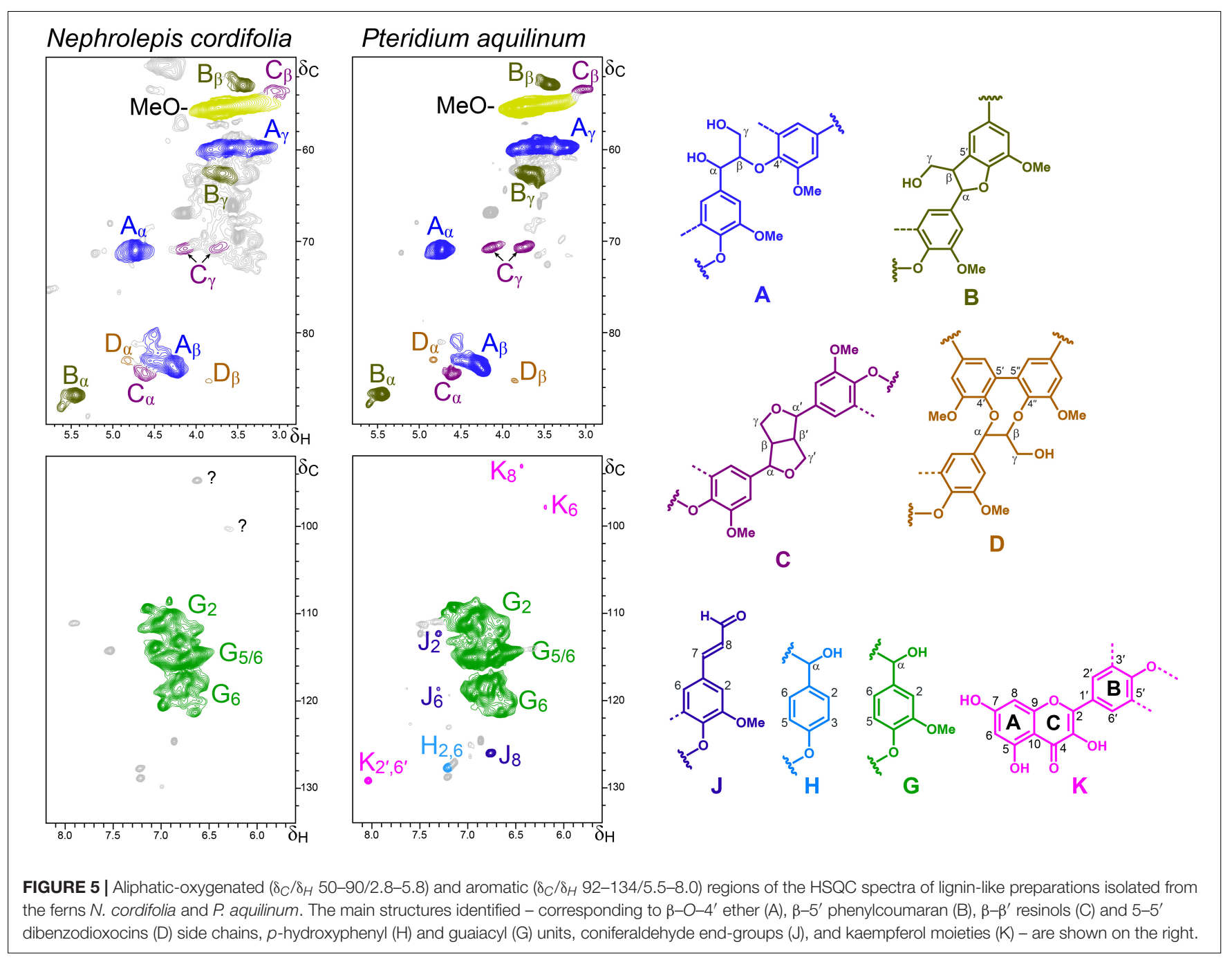

Cycadopsida) and E. fragilis (class Gnetopsida), were also studied in some detail by HSQC NMR (Figure 6).

The aromatic region of the HSQC spectrum of the C. revoluta lignin-like fraction was clearly dominated by correlations signals corresponding to G-lignin units. Cross-signals of H-lignin units, coniferaldehyde end-groups (J) and flavonoids were also detected, albeit in considerably lower amounts. The flavonoid signals were assigned to amentoflavone (Am) and naringenin $(\mathrm{N})$ moieties with the aid of authentic standards (Supplementary Figure 1). The presence of amentoflavone in the lignin fraction is not surprising as several amentoflavonederived compounds have been reported among the C. revoluta extractives (Moawad et al., 2010, 2014). In the aliphaticoxygenated region of the spectrum, typical signals of different lignin substructures, including $\beta-O-4^{\prime}$ alkyl-aryl ether (A), $\beta-5^{\prime}$ phenylcoumaran (B), $\beta-\beta^{\prime}$ resinol (C) and $5-5^{\prime}$ dibenzodioxocin (D) linkages were also detected. The relative abundances of the above substructures are provided in Table 3.

In contrast, the HSQC spectrum of the E. fragilis lignin revealed an H-G-S type polymer enriched in S-lignin units
(S/G ratio of 2.6). Similar lignin composition in Gnetopsida species have been observed in the related Ephedra viridis Coville by thioacidolysis (Ros et al., 2007), Ephedra sinica Stapf by $\mathrm{CuO}$ alkaline degradation (Jin et al., 2007b) and Gnetum gnemon L. by ozonation and NMR (Nawawi et al., 2016). Therefore, the appearance of S-lignin in E. fragilis is another case of parallel and convergent evolution of S-lignin between primitive vascular plants and angiosperms. The HSQC analysis of the E. fragilis lignin also revealed structural details (linkages and substructures). In this way, we found that the S-enriched lignin of E. fragilis is mainly composed of $\beta-O-4^{\prime}$ substructures $(81 \%)$, followed by lower amounts of $\beta-\beta^{\prime}$ resinols $(11 \%)$ and $\beta-5^{\prime}$ phenylcoumaran (7\%) and the absence of dibenzodioxocins (Table 3). The lower contents of dibenzodioxocin and phenylcoumarans in the E. fragilis lignin-like fraction, compared with C. revoluta, seems to be related to its higher $S / G$ ratio. Phenylcoumaran structures are composed of at least one G-lignin unit (and the second can be either G- or S-), while two G-lignin units are involved in the dibenzodioxocin structures (Sunits cannot form dibenzodioxocin structures). In addition, 


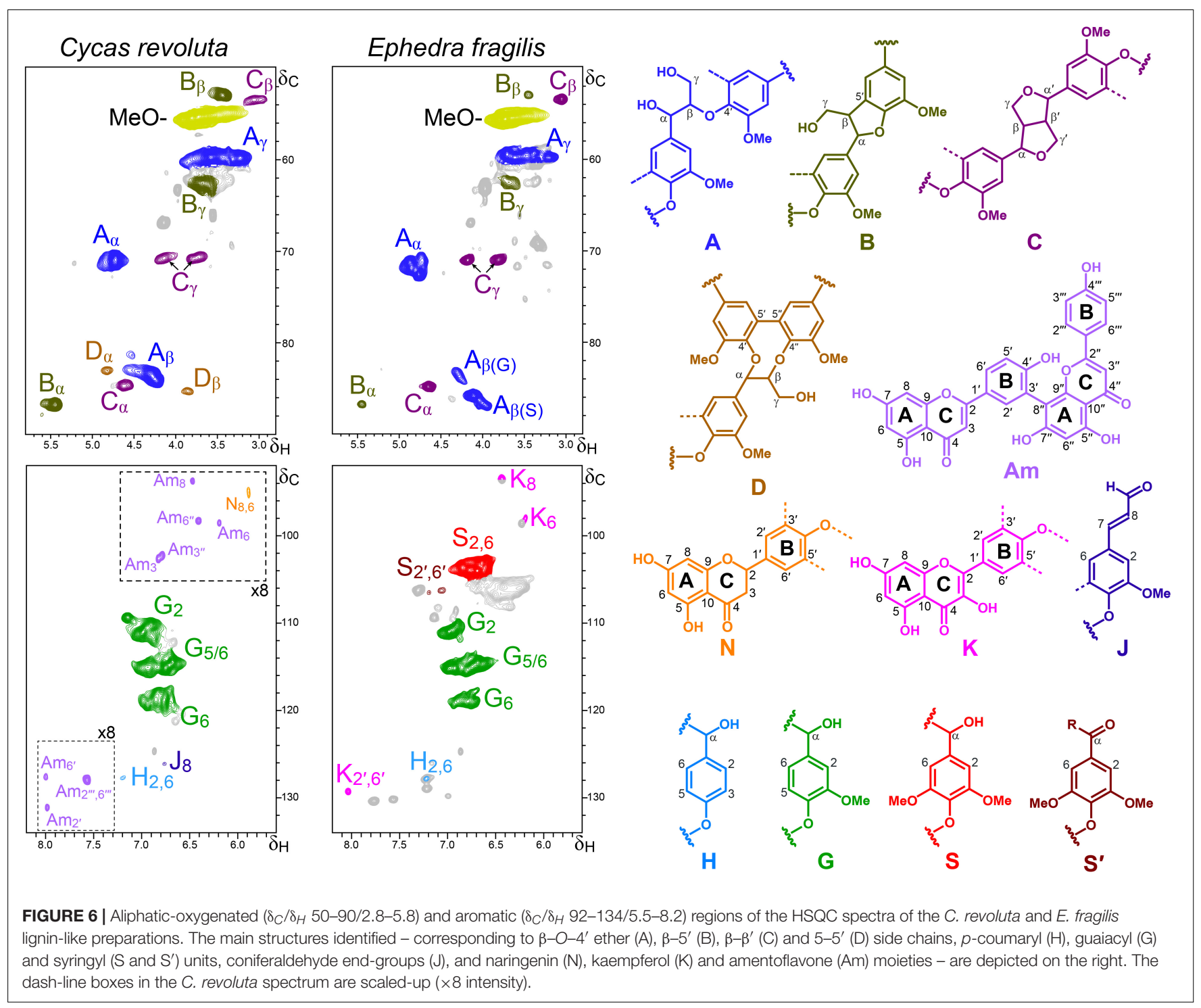

signals from flavonoids were also detected in the aromatic region of the spectrum (Figure 6), some of which were assigned to the flavonol kaempferol by comparison with an authentic standard (Supplementary Figure 1). As found in the abovementioned Selaginella, investigated as a reference system for metabolic evolution (Weng and Noel, 2013), lignin in E. fragilis and some other Gnetales species have also been found to incorporate S-units (Logan and Thomas, 1985) through convergent evolution.

\section{CONCLUSION}

Lignins from precursors synthesized through the classical monolignol biosynthetic route (yielding $p$-coumaryl, coniferyl and sinapyl alcohols) were not significantly detected in the two moss species, as the more ancestral plants analyzed. In agreement with their contribution to land colonization by vascular plants,
G lignins were found from lycophytes to ferns and ancient gymnosperms (cycads and gnetophytes). However, they were hardly detected in the gnetophyte E. palustre characterized by its limited vascular development. Then, these G-type primitive lignins, which would also include flavonoids and minor H-type units, incorporated S-type units in several parallel and convergent evolutionary events. In this way, we found S-rich lignins in the lycophyte $S$. kraussiana (S/G ratio of 2.1) and the gnetophyte E. fragilis (S/G ratio of 2.6), before their final acquisition by modern angiosperms. In this way, the presence of $S$ lignin paralleled trunk secondary thickening in different groups of plants characterized by their extant and/or ancestral arborescent development. In fact, it has been suggested that S-lignin units would have appeared up to five times during plant evolution (Novo-Uzal et al., 2012).

Plant flavonoids and lignin-like polymers have existed concomitantly since the first land plants appeared. They are believed to play a key role as UV screens due to their aromatic and 
partially phenolic nature (Clayton et al., 2018; Davies et al., 2020), although it is likely that the amount of flavonoids in the ligninlike fractions has been reduced as terrestrial plants have evolved. To a greater or lesser extent, flavonoids were detected within the lignin-like fractions of all the primitive plants studied here (from mosses to ancient gymnosperms). The B-ring flavonoids derives from the general phenylpropanoid biosynthetic pathway. Interestingly, all the flavonoids identified in the lignin-like preparations present a B-ring similar to the H-lignin units (as found in apigenin, naringenin and kaempferol). Flavonoids with a B-ring similar to G- and S-lignin units, and even in the form of catechol or pyrogallol, have been reported in extracts of most of these primitive plants (Nakabayashi, 1955; Geiger et al., 1997; Weng and Noel, 2013; Negm et al., 2016) but, due to unknown reasons, they do not incorporate into their ligninlike fractions.

Flavonoid incorporation into the lignin polymer is not a new topic. It was described that tricin [5,7-dihydroxy-2-(4-hydroxy3,5-dimethoxyphenyl)-4H-chromen-4-one] is incorporated into the lignin of wheat straw and other monocots (del Río et al., 2012; Rencoret et al., 2013; Lan et al., 2015, 2016b). However, this is in contrast to ancestral species that do not incorporate G/S-type B-ring containing flavonoids, as mentioned above. Other flavonoids, such as apigenin and naringenin, are also compatible with lignification, as shown in geneticallymodified plants (Lam et al., 2017, 2019). In the present work, we report for the first time the presence of naringenin, apigenin, kaempferol, and amentoflavone in the lignin-like fraction isolated from several wild ancestral plants, as confirmed by the corresponding HSQC signals in flavonoid-containing in vitro synthesized DHPs. Research is currently underway to confirm whether these flavonoids are covalently bound to the lignin polymer.

\section{DATA AVAILABILITY STATEMENT}

The raw data supporting the conclusions of this article will be made available by the authors, without undue reservation.

\section{REFERENCES}

Banks, J. A. (2009). Selaginella and 400 million years of separation. Annu. Rev. Plant Biol. 60, 223-238. doi: 10.1146/annurev.arplant.59.032607.092851

Bateman, R. M. (1996). "Nonfloral homoplasy and evolutionary scenarios in living and fossil land plants," in Homoplasy; The Recurrence Of Similarity In Evolution, eds M. J. Sanderson and L. Hufford (Cambridge, Massachusetts: Academic Press), 91-130. doi: 10.1016/b978-012618030-5/50006-x

Björkman, A. (1956). Studies on finely divided wood. Part I. Extraction of lignin with neutral solvents. Sven. Papperstidn 13, 477-485.

Clayton, W. A., Albert, N. W., Thrimawithana, A. H., McGhie, T. K., Deroles, S. C., Schwinn, K. E., et al. (2018). UVR8-mediated induction of flavonoid biosynthesis for UVB tolerance is conserved between the liverwort Marchantia polymorpha and flowering plants. Plant J. 96, 503-517. doi: 10.1111/tpj.14044

Davies, K. M., Jibran, R., Zhou, Y., Albert, N. W., Brummell, D. A., Jordan, B. R., et al. (2020). The evolution of flavonoid biosynthesis: a bryophyte perspective. Front. Plant Sci. 11:7. doi: 10.3389/fpls.2020.00007

del Río, J. C., Rencoret, J., Gutierrez, A., Elder, T., Kim, H., and Ralph, J. (2020). Lignin monomers from beyond the canonical monolignol biosynthetic

\section{AUTHOR CONTRIBUTIONS}

JR: work design and supervision, methodology development, chemical characterization of lignin, and contribution to first and final draft writing. AG: funding acquisition and final draft writing. GM: isolation of lignin-like fractions. JCdR: contribution to pyrolysis and NMR data interpretation. YT and PYL: DHP preparation. MP-B and FJR-D: sample preparation. JMB: collection of plant materials. ATM: work design, supervision, and contribution to first and final draft writing. All authors contributed to the article and approved the version submitted.

\section{FUNDING}

This work was funded by the Spanish Ministry of Industry, Economy and Competitiveness projects BIO2017-86559-R, AGL2017-83036-R, and PID2020-118968RB-I00, cofinanced by FEDER funds, by the Junta de Andalucía project P20-00017, and by the CSIC projects PIE-202120E019 and PIE-202040E185. We would like to acknowledge the support of the publication fee by the CSIC Open Access Publication Support Initiative through its Unit of Information Resources for Research (URICI).

\section{ACKNOWLEDGMENTS}

The authors would like to thank Manuel Angulo for his technical support with the acquisition of the NMR spectra at the NMR facilities of the General Research Services of the University of Seville (SGI-CITIUS).

\section{SUPPLEMENTARY MATERIAL}

The Supplementary Material for this article can be found online at: https://www.frontiersin.org/articles/10.3389/fpls.2021. 740923/full\#supplementary-material

pathway - Another brick in the wall. ACS Sustain. Chem. Eng. 8, 4997-5012. doi: 10.1021/acssuschemeng.0c01109

del Río, J. C., Rencoret, J., Gutiérrez, A., Lan, W., Kim, H., and Ralph, J. (2021). "Lignin Monomers Derived from the Flavonoid and Hydroxystilbene Biosynthetic Pathways," in Recent Advances in Polyphenol Research Vol. 7, eds J. D. Reed, V. A. P. de Freitas, and S. Quideau (Hoboken: John Wiley \& Sons Ltd), 177-206. doi: 10.1002/978111954 5958.ch7

del Río, J. C., Rencoret, J., Prinsen, P., Martínez, A. T., Ralph, J., and Gutiérrez, A., (2012). Structural characterization of wheat straw lignin as revealed by analytical pyrolysis, 2D-NMR, and reductive cleavage methods. J. Agric. Food Chem. 60, 5922-5935. doi: 10.1021/jf301002n

Erickson, M., and Miksche, G. E. (1974). On the occurrence of lignin or polyphenols in some mosses and liverworts. Phytochemistry 13, 2295-2299. doi: 10.1016/0031-9422(74)85042-9

Espiñeira, J. M., Novo Uzal, E., Gómez Ros, L. V., Carrión, J. S., Merino, F., Ros Barceló, A., et al. (2011). Distribution of lignin monomers and the evolution of lignification among lower plants. Plant Biol. 13, 59-68. doi: 10.1111/j.14388677.2010.00345.x 
Evtuguin, D. V., Neto, C. P., Silva, A. M. S., Domingues, P. M., Amado, F. M. L., Robert, D., et al. (2001). Comprehensive study on the chemical structure of dioxane lignin from plantation Eucalyptus globulus wood. J. Agric. Food Chem. 49, 4252-4261. doi: 10.1021/jf010315d

Fujimoto, A., Matsumoto, Y., Chang, H. M., and Meshitsuka, G. (2005). Quantitative evaluation of milling effects on lignin structure during the isolation process of milled wood lignin. J. Wood Sci. 51, 89-91. doi: 10.1007/ s10086-004-0682-7

Geiger, H., Seeger, T., Zinsmeister, H. D., and Frahm, J.-P. (1997). The occurrence of flavonoids in arthrodontous mosses-an account of the present knowledge. J. Hattori. Bot. Lab. 83, 273-308.

Grotewold, E. (2006). The Science of Flavonoids. New York, NY USA: Springer Science and Business Media, Inc. doi: 10.1007/0-387-28822-8

Imperato, F. (1996). Kaempferol 3-O-(5"-feruloylapioside) from Pteridium aquilinum. Phytochemistry 43, 1421-1423. doi: 10.1016/S0031-9422(96)00 $428-1$

Jermy, A. C. (1990). "Selaginellaceae," in Pteridophytes and Gymnosperms. The Families and Genera of Vascular Plants, eds K. U. Kramer and P. S. Green (Berlin, Heidelberg: Springer Berlin Heidelberg), 39-45. doi: 10.1007/978-3662-02604-5_11

Jin, Z., Matsumoto, Y., Tange, T., Akiyama, T., Higuchi, M., Ishii, T., et al. (2005). Proof of the presence of guaiacyl-syringyl lignin in Selaginella tamariscina. J. Wood Sci. 51, 424-426. doi: 10.1007/s10086-005-0 725-8

Jin, Z., Matsumoto, Y., Tange, T., and Iiyama, K. (2007a). Structural characteristics of lignin in primitive pteridophytes: Selaginella species. J. Wood Sci. 53, 412418. doi: $10.1007 / \mathrm{s} 10086-006-0872-6$

Jin, Z., Shao, S., Katsumata, K. S., and Iiyama, K. (2007b). Lignin characteristics of peculiar vascular plants. J. Wood Sci. 53, 520-523. doi: 10.1007/s10086-0070891-y

Kenrick, P., and Crane, P. R. (1997). The origin and early evolution of plants on land. Nature 389, 33-39. doi: 10.1038/37918

Kim, H., Padmakshan, D., Li, Y., Rencoret, J., Hatfield, R. D., and Ralph, J. (2017). Characterization and elimination of undesirable protein residues in plant cell wall materials for enhancing lignin analysis by solution-state Nuclear Magnetic Resonance spectroscopy. Biomacromolecules 18, 4184-4195. doi: 10.1021/acs. biomac.7b01223

Lam, P. Y., Lui, A. C. W., Yamamura, M., Wang, L., Takeda, Y., Suzuki, S., et al. (2019). Recruitment of specific flavonoid B-ring hydroxylases for two independent biosynthesis pathways of flavone-derived metabolites in grasses. New Phytol. 223, 204-219. doi: 10.1111/nph.15795

Lam, P. Y., Tobimatsu, Y., Takeda, Y., Suzuki, S., Yamamura, M., Umezawa, T., et al. (2017). Disrupting flavone synthase II alters lignin and improves biomass digestibility. Plant Physiol. 174, 972-985. doi: 10.1104/pp.16.0 1973

Lan, W., Lu, F., Regner, M., Zhu, Y., Rencoret, J., Ralph, S. A., et al. (2015). Tricin, a flavonoid monomer in monocot lignification. Plant Physiol. 167, 1284-1295. doi: $10.1104 /$ pp. 114.253757

Lan, W., Rencoret, J., Lu, F., Karlen, S. D., Smith, B. G., Harris, P. J., et al. (2016b). Tricin-lignins: occurrence and quantitation of tricin in relation to phylogeny. Plant J. 88, 1046-1057. doi: 10.1111/tpj.13315

Lan, W., Morreel, K., Lu, F., Rencoret, J., del Río, J. C., Voorend, W., et al. (2016a). Maize tricin-oligolignol metabolites and their implications for monocot lignification. Plant Physiol. 171, 810-820. doi: 10.1104/pp.16.0 2012

Logan, K. J., and Thomas, B. A. (1985). Distribution of lignin derivatives in plants. New Phytol. 99, 571-585. doi: 10.1111/j.1469-8137.1985.tb0 3685. $\mathrm{x}$

Moawad, A., Hetta, M., Zjawiony, J. K., Ferreira, D., and Hifnawy, M. (2014). Two new dihydroamentoflavone glycosides from Cycas revoluta. Nat. Prod. Res. 28, 41-47. doi: 10.1080/14786419.2013.832675

Moawad, A., Hetta, M., Zjawiony, J. K., Jacob, M. R., Hifnawy, M., Marais, J. P. J., et al. (2010). Phytochemical investigation of Cycas circinalis and Cycas revoluta leaflets: moderately active antibacterial biflavonoids. Planta Med. 76, 796-802. doi: $10.1055 / \mathrm{s}-0029-1240743$

Nakabayashi, T. (1955). Isolation of astragalin and isoquercitrin from bracken, Pteridium aquilinum. J. Agric. Chem. Soc. Japan 19, 104-109. doi: 10.1080/ 03758397.1955.10857273
Nawawi, D. S., Syafii, W., Akiyama, T., and Matsumoto, Y. (2016). Characteristics of guaiacyl-syringyl lignin in reaction wood in the gymnosperm Gnetum gnemon L. Holzforschung 70, 593-602. doi: 10.1515/hf-20150107

Negm, W. A., Ibrahim, A. E. R. S., Abo El-Seoud, K. A., Attia, G. I., and Ragab, A. E. (2016). A new cytotoxic and antioxidant amentoflavone monoglucoside from Cycas revoluta Thunb growing in Egypt. J. Pharm. Sci. Res. 8, 343-350.

Nimz, H. H., and Tutschek, R. (1977). Kohlenstoff-13-NMR-Spektren von Ligninen, 7. Zur Frage des Ligningehalts von Moosen (Sphagnum magellanicum Brid.). Holzforschung 31, 101-106. doi: 10.1515/hfsg.1977.31.4.101

Novo-Uzal, E., Pomar, F., Gómez Ros, L. V., Espiñeira, J. M., and Ros Barceló, A. (2012). "Chapter 9 - Evolutionary History of Lignins," in Lignins: Biosynthesis, Biodegradation and Bioengineering, eds L. Jouanin and C. Lapierre (Cambridge, Massachusetts: Academic Press), 309-350. doi: 10.1016/B978-0-12-416023-1. 00009-4

Qian, Y., Qiu, X., and Zhu, S. (2015). Lignin: a nature-inspired sun blocker for broad-spectrum sunscreens. Green Chem. 17, 320-324. doi: 10.1039/ c4gc01333f

Ralph, J., and Hatfield, R. D. (1991). Pyrolysis-GC-MS characterization of forage materials. J. Agric. Food Chem. 39, 1426-1437. doi: 10.1021/jf00008 a014

Ralph, J., Lapierre, C., and Boerjan, W. (2019). Lignin structure and its engineering. Curr. Opin. Biotechnol. 56, 240-249. doi: 10.1016/j.copbio.2019.02.019

Ralph, J., Lundquist, K., Brunow, G., Lu, F., Kim, H., Schatz, P. F., et al. (2004). Lignins: natural polymers from oxidative coupling of 4hydroxyphenylpropanoids. Phytochem. Rev. 3, 29-60. doi: 10.1023/B:PHYT. 0000047809.65444.a4

Raven, J. A. (1984). Physiological correlates of the morphology of early vascular plants. Bot. J. Linn. Soc. 88, 105-126. doi: 10.1111/j.1095-8339.1984.tb01566.x

Rencoret, J., del Río, J. C., Nierop, K. G. J., Gutiérrez, A., and Ralph, J. (2016). Rapid Py-GC/MS assessment of the structural alterations of lignins in genetically modified plants. J. Anal. Appl. Pyrolysis 121, 155-164. doi: 10.1016/j.jaap.2016. 07.016

Rencoret, J., Marques, G., Serrano, O., Kaal, J., Martínez, A. T., del Río, J. C., et al. (2020). Deciphering the unique structure and acylation pattern of Posidonia oceanica lignin. ACS Sustain. Chem. Eng. 8, 12521-12533. doi: 10. 1021/acssuschemeng.0c03502

Rencoret, J., Prinsen, P., Gutiérrez, A., Martínez, A. T., and del Río, J. C. (2015). Isolation and structural characterization of the milled wood lignin, dioxane lignin, and cellulolytic lignin preparations from brewer's spent grain. J. Agric. Food Chem. 63, 603-613. doi: 10.1021/jf505808c

Rencoret, J., Ralph, J., Marques, G., Gutiérrez, A., Martínez, A. T., and del Río, J. C. (2013). Structural characterization of lignin isolated from coconut (Cocos nucifera) coir fibers. J. Agric. Food Chem. 61, 2434-2445. doi: 10.1021/jf30 4686x

Ros, L. V. G., Gabaldón, C., Pomar, F., Merino, F., Pedreño, M. A., and Barceló, A. R. (2007). Structural motifs of syringyl peroxidases predate not only the gymnosperm-angiosperm divergence but also the radiation of tracheophytes. New Phytol. 173, 63-78. doi: 10.1111/j.1469-8137.2006.01898.x

Setyawan, A. D. (2019). Review: natural products from Genus Selaginella (Selaginellaceae). Nusant. Biosci. 3, 44-58. doi: 10.13057/nusbiosci/n030107

Sievers, H., Burkhardt, G., Becker, H., and Zinsmeister, H. D. (1992). Hypnogenols and other dihydroflavonols from the moss Hypnum cupressiforme. Phytochemistry 31, 3233-3237. doi: 10.1016/0031-9422(92)83482-E

Swamy, R. C., Kunert, O., Schühly, W., Bucar, F., Ferreira, D., Rani, V. S., et al. (2006). Structurally unique biflavonoids from Selaginella chrysocaulos and Selaginella bryopteris. Chem. Biodivers. 3, 405-414. doi: 10.1002/cbdv. 200690044

Tobimatsu, Y., Takano, T., Kamitakahara, H., and Nakatsubo, F. (2008). Studies on the dehydrogenative polymerizations of monolignol $\beta$-glycosides. Part 3: horseradish peroxidase-catalyzed polymerizations of triandrin and isosyringin. J. Wood Chem. Technol. 28, 69-83. doi: 10.1080/02773810802124787

Weng, J. K., Akiyama, T., Ralph, J., and Chapple, C. (2011). Independent recruitment of an $O$-methyltransferase for syringyl lignin biosynthesis in Selaginella moellendorffii. Plant Cell 23, 2708-2724. doi: 10.1105/tpc.110. 081547

Weng, J. K., and Chapple, C. (2010). The origin and evolution of lignin biosynthesis. New Phytol. 187, 273-285. doi: 10.1111/j.1469-8137.2010.03327.x 
Weng, J. K., Li, X., Stout, J., and Chapple, C. (2008). Independent origins of syringyl lignin in vascular plants. Proc. Natl. Acad. Sci. U. S. A. 105, 7887-7892. doi: 10.1073/pnas.0801696105

Weng, J. K., and Noel, J. P. (2013). Chemodiversity in Selaginella: a reference system for parallel and convergent metabolic evolution in terrestrial plants. Front. Plant Sci. 4:119. doi: 10.3389/fpls.2013.00119

Xie, M., Zhang, J., Tschaplinski, T. J., Tuskan, G. A., Chen, J. G., and Muchero, W. (2018). Regulation of lignin biosynthesis and its role in growth-defense tradeoffs. Front. Plant Sci. 9:1427. doi: 10.3389/fpls.2018.0 1427

Yamaguchi, L. F., and Kato, M. J. (2012). Diurnal and seasonal changes in biflavonoids biosynthesis in Araucaria angustifolia needles. Glob. J. Biochem. $3,1-7$.

Yu, S., Yan, H., Zhang, L., Shan, M., Chen, P., Ding, A., et al. (2017). A review on the phytochemistry, pharmacology, and pharmacokinetics of amentoflavone, a naturally-occurring biflavonoid. Molecules 22:299. doi: 10. 3390/molecules22020299
Conflict of Interest: The authors declare that the research was conducted in the absence of any commercial or financial relationships that could be construed as a potential conflict of interest.

Publisher's Note: All claims expressed in this article are solely those of the authors and do not necessarily represent those of their affiliated organizations, or those of the publisher, the editors and the reviewers. Any product that may be evaluated in this article, or claim that may be made by its manufacturer, is not guaranteed or endorsed by the publisher.

Copyright (C) 2021 Rencoret, Gutiérrez, Marques, del Río, Tobimatsu, Lam, Pérez-Boada, Ruiz-Dueñas, Barrasa and Martínez. This is an open-access article distributed under the terms of the Creative Commons Attribution License (CC BY).

The use, distribution or reproduction in other forums is permitted, provided the original author(s) and the copyright owner(s) are credited and that the original publication in this journal is cited, in accordance with accepted academic practice. No use, distribution or reproduction is permitted which does not comply with these terms. 